\title{
An attempt to induce an immunomodulatory effect in rowers with spirulina extract
}

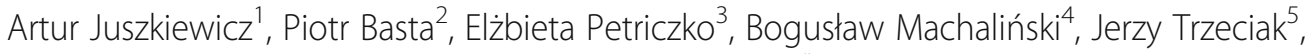
Karolina Łuczkowska ${ }^{4}$ and Anna Skarpańska-Stejnborn ${ }^{5^{*}}$

\begin{abstract}
Background: The aim of this study was to analyze the response of selected components of the immune system in rowers to maximal physical exercise, and to verify if this response can be modulated by supplementation with spirulina (cyanobacterium Spirulina platensis).

Method: The double-blind study included 19 members of the Polish Rowing Team. The subjects were randomly assigned to the supplemented group $(n=10)$, receiving $1500 \mathrm{mg}$ of spirulina extract for 6 weeks, or to the placebo group $(n=9)$. The participants performed a 2000-m test on a rowing ergometer at the beginning (1st examination) and at the end of the supplementation period (2nd examination). Blood samples were obtained from the antecubital vein prior to each exercise test, $1 \mathrm{~min}$ after completing the test, and after a 24-h recovery period. Subpopulations of T regulatory lymphocytes (Tregs) [CD4+/CD25+/CD127-], cytotoxic lymphocytes (CTLs) [CD8

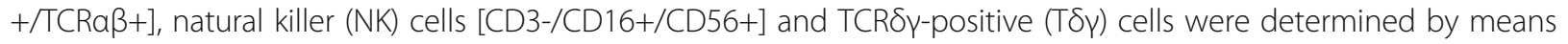
of flow cytometry.
\end{abstract}

Results: On the 2nd examination, athletes from the supplemented group showed neither a post-exercise increase in Treg count nor a post-recovery decrease in T $\delta \gamma$ cell count (both observed in the placebo group), and presented with significantly lower values of Treg/CTL prior to and after the exercise. During the same examination, rowers from the placebo group showed a significant post-recovery increase in Treg/(NK $+T \delta \gamma+C T L)$ ratio, which was absent in the supplemented group.

Conclusion: The results of this study imply that supplementation with spirulina extract may protect athletes against a deficit in immune function (especially, anti-infectious function) associated with strenuous exercise, and may cause a beneficial shift in "overtraining threshold" preventing a radical deterioration of immunity.

Keywords: Spirulina, Supplementation, Flow cytometry, Inflammation, Strenuous exercise, Rowers

\section{Background}

Previous studies demonstrated that influence of physical exercise on the immune system may vary considerably depending on the type of training load. Regular, moderate physical exercise improves immunity, exerting a beneficial effect on the immune system [1]. However, an opposite effect may be exerted by strenuous exercise

\footnotetext{
* Correspondence: ankass@poczta.onet.pl

${ }^{5}$ Department of Morphological and Health Sciences, Faculty of Physical Culture in Gorzów Wlkp. Poland, 13 Estkowskiego Str, 66 - 400 Gorzów Wlkp, Poland

Full list of author information is available at the end of the article
}

which was shown to activate immunological and endocrine mechanisms similar to those prevailing in chronic stress, trauma and sepsis [2,3]. This may lead, in particular in high-performance athletes, to impairment of immune response and resultant greater susceptibility to infections, e.g. respiratory tract infections $[4,5]$. Previous studies demonstrated that a decrease in salivary IgA concentrations and enhanced synthesis of antigenstimulated IL-10 correlate strongly with an increase in the incidence of upper respiratory tract infections in athletes. However, the exact etiological mechanism of the immunity impairment is still not fully understood $[6,7]$. 
Moreover, no other markers of the exercise-induced immunity impairment predisposing to upper respiratory tract infections have been established thus far [7].

Krüger et al. [8] and Adams et al. [9] showed that strenuous exercise leads to a transient increase in circulating lymphocyte count, followed by a persistent decrease in this parameter, even to the point of lymphopenia. According to these authors, after strenuous exercise, lymphocytes may migrate to some critical regions, including muscles, particularly resulting in a shift in lymphocyte subpopulations [10]. Effector lymphocytes, such as natural killer (NK) cells, cytotoxic T CD8+ cells (CTLs), TCR $\delta$-positive (T $\delta \gamma)$ cells and regulatory $\mathrm{T}$ cells (Tregs), are a key component of human immune system and play a crucial role in cell-mediated immune response. Interactions between cytotoxic lymphocytes and Tregs are of particular interest to researchers dealing with various pathological conditions (e.g. autoimmune diseases and neoplasms) [11-19]. In contrast, only few previous studies have addressed the problem associated with a shift in lymphocyte subpopulations and interactions between various types of immune cells in athletes. Furthermore, the results of these sparse studies are generally inconclusive.

Many recent studies dealt with Tregs, a lymphocyte subpopulation that can be identified on flow cytometry based on the expression of CD4, CD25 and FOXP3 antigens (or lack of CD 127) [20]. This growing research interest is associated with the leading role of Tregs in immune tolerance, as well as with their involvement in the control of an overactivated immune system. Under physiological conditions, Tregs represent no more than $5-10 \%$ of CD4+ lymphocytes present in peripheral blood $[20,21]$. Tregs prevent autoimmune reactions, allograft rejection, food intolerance and rejection of the fetus by the maternal immune system [20]. However, aside from these beneficial effects, they may also interfere with effector function and proliferation of cells involved in the specific and non-specific immune response, such as CTLs, NK cells, monocytes, macrophages and dendritic cells $[22,23]$. Available evidence suggests that overactivity of Tregs may result in immune impairment, potentially predisposing individuals to chronic infections or facilitate formation of metastases in cancer patients [13, 15, 18, 19, 24, 25]. Kunzmann et al. [26] showed that Tregs can inhibit phosphoantigen-induced proliferation of non-conventional highly-cytotoxic T $\delta \gamma$ cells. Furthermore, few previous studies demonstrated that repeated strenuous exercise may persistently alter absolute and relative size of lymphocyte subpopulations, causing a shift toward Tregs. This phenomenon may be inter alia reflected by an increase in the level of IL-10 synthesized by these cells, and is at least in part responsible for the resulting immunosuppression [27]. Furthermore, strenuous physical exercise may cause a decrease in the number of NK cells and CTLs $[10,28,29]$.

However, the results of previous studies analyzing immunomodulatory effects of physical exercise, either in humans or in animal models, are inconclusive. Wang et al. [30] demonstrated that 6 weeks of exhaustive highintensity exercise resulted in an increase in the number of Tregs, and altered proportions of CD4+ and CD25+ cells in murine spleen. Similar effects, however, were not observed in mice subjected to moderate-intensity exercise. These findings were partially confirmed by Wilson et al. [31] who showed that acute, intense swimming exercise contributed to an increase in the number of circulating Tregs in adolescent athletes. However, quite contradictive results were obtained by Perry et al. [32] when analyzing the effects of strenuous endurance exercise in marathon runners and half-ironman triathletes, reporting a substantial post-exercise decrease in the number of circulating Tregs.

Addition of supplements with established immunomodulatory properties to athletes' diet may constitute a form of mild and safe intervention to restore immune balance. A cyanobacterium, Spirulina platensis (SPR) is a supplement with a good safety profile and established immunomodulatory potential [33, 34]. Many previous studies document beneficial effects of SPR on the immune system in both animals and humans $[34,35]$. SPR is rich in protein, vitamins, minerals and unsaturated fatty acids, especially gammalinolenic acid. Moreover, it contains phycocyanins and lipopolysaccharides, key components of cell walls in Gramnegative bacteria [36]. Many authors showed that SPR may stimulate macrophages to synthesize IL-12, a cytokine that promotes production of INT- $\gamma$ by NK cells [37]. Published evidence suggests that supplementation with SPR may also prevent replication of viruses, and thus may be helpful in control of many viral infections, such as chickenpox, cytomegaly, measles, mumps, influenza and $\operatorname{HIV}[38,39]$. Løbner et al. [40] showed that supplementation with a polysaccharide extract of SPR stimulated production of IL2 , INT- $\gamma$ and TNF-alpha, while down-regulating the synthesis of IL-4 in antigen-activated lymphocytes from healthy volunteers. A decrease in IL-4 production was also observed in SPR-supplemented (2 g daily for 12 weeks) patients with allergic rhinitis. Since IL-4 was previously shown to inhibit spontaneous apoptosis of Tregs, its downregulation likely enhances programmed death of these cells. Theoretically, the resultant decrease in Treg count should promote a cell-mediated immune response [41, 42]. Indeed, a 7-day supplementation with SPR extract increased NK cell activity in healthy persons [43]. Moreover, administration of SPR enhanced antitumor activity in syngeneic tumor-implanted mice [35].

Many previous studies demonstrated that SPR may cause a shift in Th1/Th2 balance toward Th1-dominant 
immunity. This justifies the analysis of SPR's effects in athletes, in whom strenuous physical exercise may impair immunity and disrupt balance between cytotoxic lymphocytes and Tregs. However, to the best of our knowledge, none of the previous studies analyzed the effects of SPR on the number of Tregs, NK cells, CTLs and $T \delta \gamma$ cells in this group. Nevertheless, the studies analyzing suppressive effects of Tregs and cytotoxicity of NK cells, T $\delta \gamma$ cells and CTLs may produce flawed results unless other components of the immune system are considered. Exposure to an extreme stressor, such as maximal exercise, results in an increase/decrease in the number of cytotoxic lymphocytes, counterbalanced with a decrease/increase in Treg count. It is the outcome of these processes, which eventually reflects the influence of exercise on immune function. Since previous studies documented a plethora of interactions (either direct or cytokine-mediated) between various lymphocyte subpopulations, we searched for possibly most accurate marker of these complex relationships. Other authors [12, 17, 26, 44] demonstrated that Treg to effector $\mathrm{T}$ cell ratio reflects suppressive effects of the former on various effector cells more accurately than a simple determination of their counts. To the best of our knowledge, none of the previous studies examined exercise- induced changes in these parameters in sportspersons. Therefore, the aim of this study was to analyze changes in Treg/T $\delta \gamma$, Treg/NK, Treg/CTL and Treg/(NK + T $\delta \gamma+\mathrm{CTL})$ ratios in SPRsupplemented athletes subjected to strenuous exercise; to the best of our knowledge, none of the previous studies examined exercise-induced changes in these parameters in sportspersons.

\section{Methods}

\section{Study population}

The study included 19 men, all members of the Polish Rowing Team (15 heavy-weight and 4 light-weight rowers). Basic characteristics and sport classes of the athletes are presented in Table 1. The study was conducted between March and May, during a 6-week training camp, scheduled between the preparatory and competitive phase of the yearly training cycle. The characteristics of the training profile, such as its intensity, volume (in minutes) and type (specific, i.e. rowing:

Table 1 Basic characteristics of the study groups

\begin{tabular}{lll}
\hline Parameters & $\begin{array}{l}\text { Supplemented group } \\
(n=10)\end{array}$ & $\begin{array}{l}\text { Placebo group } \\
(n=9)\end{array}$ \\
\hline Age (years) & $20.4 \pm 0.84$ & $20.0 \pm 0.71$ \\
Body mass (kg) & $84.4 \pm 8.43$ & $87.1 \pm 5.80$ \\
Body height (cm) & $192.3 \pm 4.32$ & $190.8 \pm 3.89$ \\
Duration of training (years) & $7.3 \pm 1.3$ & $6.8 \pm 1.8$ \\
\hline
\end{tabular}

Values represent means \pm standard deviations. No statistically significant differences were found for all intergroup comparisons $(P>0.05)$ endurance, technical, speed, etc., and nonspecific: jogging, strength) were recorded on a daily basis. The intensity of the training was classified based on the lactate acid (LA) threshold $(4 \mathrm{mmol} / \mathrm{L})$, as extensive (below the LA threshold), highly intensive (above the LA threshold), and extremely intensive (control tests) (Table 2).

\section{Food intake}

Throughout the study period, the athletes accommodated at one of the Olympic Training Centers, whereby they had all their meals. Their regular menu consisted of a mixed diet, providing the recommended dietary allowance (RDA) of carbohydrates, proteins, fats and micronutrients (vitamins and minerals), in line with the Polish Nutrition Society guidelines [45]. Daily intakes of food, calories, fruits and vegetables were the same throughout the study period. All athletes were provided with a bottled mineral water and instructed about the necessity of immediate fluid repletion, in particular prior to and after the exercise.

The study subjects declared that they had ceased all drugs, medications and dietary supplements at least 2 weeks prior to the study, and did not use them throughout the entire study period.

\section{Experimental procedure}

Athletes who were randomized to the supplemented group $(n=10)$ received capsules with Spirulina platensis extract, manufactured by GAL (Poznan, Poland). A single 596-mg capsule was made of $500 \mathrm{mg}$ Spirulina platensis containing $5.9 \mathrm{mg}$ chlorophyll, $0.093 \mathrm{mg}$ vitamin $\mathrm{B}_{6}, 6.5 \mu \mathrm{g}$ vitamin $\mathrm{K}, 0.8 \mu \mathrm{g}$ vitamin $\mathrm{B}_{12}, 3.5 \mu \mathrm{g}$ selenium and $9.0 \mu$ g iodine, coated with $96 \mathrm{mg}$ gelatin. The subjects were asked to take one capsule before each of their three main meals during the day, for a period of 6 weeks, which corresponded to $1500 \mathrm{mg}$ of spirulina extract per day. Athletes randomized to the placebo group $(n=9)$ received visually identical capsules with calcium gluconate (500 mg per capsule).

\section{Training program}

Training volumes (expressed in minutes per day) during a week preceding the 1st and the 2nd examination, particularly for extensive rowing, intensive rowing, kilometers, and extensive non-specific training, are shown in Table 2. During the load training phase (before the 1st examination), the training volume amounted to $1130 \mathrm{~min} \cdot \mathrm{wk}^{-1}$, including approximately $49.6 \%$ of extensive rowing, $26.5 \%$ of non-specific training (e.g. power training) and $23.9 \%$ of intensive rowing. Total training volume before the 2nd examination was $940 \mathrm{~min} \cdot \mathrm{wk}^{-1}$, and included approximately $66.9 \%$ of extensive rowing, $10.7 \%$ of intensive rowing (with $5.2 \%$ of maximum-intensity control tests) and $11.7 \%$ of land training. 
Table 2 Training schedule for the week preceding blood sampling during the 1st and the 2nd examination

\begin{tabular}{|c|c|c|c|c|c|c|c|}
\hline & \multicolumn{7}{|c|}{ Days before the 1st examination } \\
\hline & 1 & 2 & 3 & 4 & 5 & 6 & 7 \\
\hline Total training time, min/day & 120 & 150 & 200 & 190 & 210 & 140 & 120 \\
\hline Time rowed, min/day & 110 & 100 & 100 & 100 & 70 & 90 & 100 \\
\hline Distance rowed, km/day & 22 & 20 & 20 & 20 & 16 & 18 & 20 \\
\hline Training for force development, min/day & - & - & 90 & - & 70 & - & - \\
\hline Extensive endurance rowing training time, min/day & 70 & 100 & 100 & 60 & 40 & 90 & 100 \\
\hline High intensity endurance rowing training time, min/day & 40 & - & - & 40 & 30 & - & - \\
\hline \multirow[t]{3}{*}{ Unspecific training (running, etc.), min/day } & 10 & 50 & 10 & 90 & 70 & 50 & 20 \\
\hline & \multicolumn{7}{|c|}{ Days before the 2 nd examination } \\
\hline & 1 & 2 & 3 & 4 & 5 & 6 & 7 \\
\hline Total training time, min/day & 110 & 120 & 100 & 160 & 200 & 120 & 130 \\
\hline Time rowed, min/day & 100 & 100 & 90 & 90 & 120 & 100 & 120 \\
\hline Distance rowed, km/day & 20 & 18 & 18 & 18 & 20 & 20 & 20 \\
\hline Training for force development, min/day & - & - & - & 60 & 60 & - & - \\
\hline Extensive endurance rowing training time, min/day & 80 & 70 & 90 & 90 & 94 & 80 & 125 \\
\hline High intensity endurance rowing training time, min/day & 6 & 9 & - & - & 12 & 20 & 5 \\
\hline Very high intensity endurance rowing training time, min/day & 14 & 21 & - & - & 14 & - & - \\
\hline Unspecific training (running, etc.), $\mathrm{min} /$ day & 10 & 20 & 20 & 10 & 20 & 20 & 10 \\
\hline
\end{tabular}

\section{Rowing performance test}

The athletes performed a controlled 2000-m time trial on the first day (prior to the supplementation) and at the end of training camp (after the supplementation). Each subject had to cover the 2000-m distance on a rowing ergometer (Concept II, Morrisville, VT USA) in as short time as possible. Because the results of both tests were taken into consideration during selection to the championship team, the athletes were well motivated to perform both tests at maximal effort. Prior to each test, the subjects performed a 5-min individual warm-up on the rowing ergometer Concept II, according to their own freely selected program.

\section{Sample treatment}

Blood samples from the antecubital vein were collected to tubes with dipotassium ethylene diamine tetra-acetic acid $\left(\mathrm{K}_{2}\right.$ EDTA) as an anticoagulant. Blood was collected before each 2000-m test (after 7-8 h of overnight fasting), 1 min after completing the test, and after a 24-h recovery period. The samples were centrifuged at $2200 \mathrm{rpm}$ for $10 \mathrm{~min}$. After removing the plasma and adding 1× Lysing Buffer (BD Biosciences), the samples were incubated in darkness for $15 \mathrm{~min}$. Then, a PBS buffer was added, and the cells were washed twice to remove all erythrocytes.

Moreover, capillary blood samples from an ear lobe were collected prior to and after each exercise test, to assess lactic acid (LA) level.

\section{Measurements}

Cytometric analysis of lymphocyte subpopulations: Tregs [CD4+/CD25+/CD127-], CTLs [CD8+/TCR $\alpha \beta+]$, NK cells [CD3-/CD16+/CD56+] T $\delta \gamma$ cells was conducted after their labeling with fluorochrome-conjugated antibodies from BD Biosciences. Cells obtained after hypotonic lysis of peripheral blood were incubated in darkness at room temperature for $20 \mathrm{~min}$ with the respective antibody at a concentration specified by the manufacturer to identify each lymphocyte subpopulation (Table 3 ). Then, the cells were washed twice with PBS buffer and left in darkness in $3.7 \%$ formaldehyde solution for $10 \mathrm{~min}$. Afterwards, the cells were again washed with PBP buffer and $100 \mu \mathrm{L}$ of DAPI solution (1 mg/mL, Thermo Fisher Scientific) were

Table 3 Antibodies used for identification of lymphocyte subpopulations

\begin{tabular}{ll}
\hline Lymphocyte subpopulation & Antibody \\
\hline Regulatory T lymphocytes & FITC Mouse Anti-Human CD4 \\
& PE Mouse Anti-Human CD25 \\
& Alexa Fluor 647 Mouse anti-Human CD127 \\
& APC Mouse Anti-Human CD8 \\
Cytotoxic lymphocytes & FITC Mouse Anti-Human TCR a 3 \\
NK cells & FITC Mouse Anti-Human CD3 \\
& PE Mouse Anti-Human CD16 \\
& APC Mouse Anti-Human CD56 \\
TCR $/ Y$ lymphocytes & FITC Mouse Anti-Human TCR $/ Y$ \\
\hline
\end{tabular}


added to stain cell nuclei. The cells were incubated in darkness at room temperature for $5 \mathrm{~min}$, washed twice, and suspended in $250 \mu \mathrm{L}$ of PBS buffer. After labeling, the cells were analyzed with a LSRII flow cytometer from BD Biosciences, coupled with BD FACSDiva software.

\section{Statistical analysis}

Statistical analyses were performed with STATISTICA v. 10.0 software package (StatSoft, Cracow, Poland). All parameters were compared using 2 (supplementation: supplemented vs. placebo) $\times 3$ (exercise: pre-exercise vs. post-exercise vs. post-recovery) repeated measures analysis of variance (ANOVA). Normal distribution of the study variables was verified with Shapiro-Wilk test. Whenever the result of ANOVA was statistically significant, Fisher's post-hoc test was conducted to identify the source of significant differences. Anthropometric characteristics of the study groups were compared with Student's unpaired $t$-test. Except from the rowing time, the results of the 2000-m tests performed prior to and after the supplementation were compared with Student's paired $t$-test, and intergroup comparisons were conducted with Student's unpaired $t$-test. The results of the 2000-m simulated rowing test were subjected to one-way ANOVA. Statistical characteristics of the study variables are presented as means $\pm \mathrm{SD}$, and the threshold of statistical significance for all tests was set at $P<0.05$.

\section{Results}

Athletes from the supplemented group and the placebo group did not differ significantly in terms of their mean age, height, body weight, and years of training (Table 1).

No significant intergroup differences were found in mean power output and total run time during the 2000$\mathrm{m}$ test performed at the beginning of the training camp. Furthermore, no significant differences in the pre- and post-test blood LA levels were documented when the results of the 1st examination were compared to those of the 2nd examination (Table 4).

Treg counts determined during the 1st and the 2nd examination are shown on Fig. 1a. ANOVA revealed a significant main effect of exercise on Treg count $(p<0.001)$.
During the 2nd examination, athletes from the placebo group showed a significant post-exercise increase in Treg count, with subsequent normalization of this parameter post-recovery $(p<0.05)$. In contrast, no significant exercise-induced changes in Treg count were observed in the supplemented group during the 2nd examination, as well as in both study groups during the 1st examination. Based on the results of ANOVA, spirulina supplementation did not exert a statistically significant effect on Treg count (main effect, $p=0.069$ ).

NK cell counts determined prior to and after supplementation with SPR extract are shown in Fig. 1b. ANOVA demonstrated a significant main effect of exercise on NK cell count $(p<0.001)$. During both the 1 st and the 2nd examination, a significant post-exercise increase in this parameter was observed in both the supplemented group and the placebo group, followed by a post-recovery normalization (solely during the 2nd examination).

$\mathrm{T} \delta \gamma$ cell counts in the study subjects are presented on Fig. 1c. Like for other previously mentioned lymphocyte subpopulations, ANOVA demonstrated a significant main effect of exercise on T $\delta \gamma$ cell count $(p<0.001)$. During the 1 st examination, pre-exercise, post-exercise and postrecovery $\mathrm{T} \delta \gamma$ cell counts did not differ significantly, in the supplemented group or placebo group. However, during the 2nd examination, a significant post-exercise decrease in $\mathrm{T} \delta \gamma$ cell count was observed in the placebo group. Nevertheless, the main effect of supplementation on $T \delta \gamma$ cell count was not statistically significant $(p=0.691)$.

ANOVA demonstrated that exercise exerted a significant main effect on CTL count $(p<0.001)$. Irrespective of the group, a significant post-exercise increase in CTL count was observed during the 1st examination (Fig. 1d). However, during the 2nd examination, the significant post-exercise increase in this parameter was observed in the placebo group, but not in the supplemented group. Furthermore, athletes from the supplemented group showed a post-recovery decrease in CTL count during the 2nd examination. However, the main effect of supplementation on CTL count did not turn out to be statistically significant on ANOVA $(p=0.333)$.

Table 4 Changes in 2,000 m rowing ergometer performance before and after supplementation

\begin{tabular}{|c|c|c|c|c|}
\hline \multirow[t]{2}{*}{ Parameters } & \multicolumn{2}{|c|}{$\begin{array}{l}\text { Supplemented group } \\
(n=10)\end{array}$} & \multicolumn{2}{|c|}{$\begin{array}{l}\text { Placebo group } \\
(n=9)\end{array}$} \\
\hline & Before & After & Before & After \\
\hline $\begin{array}{l}\text { Power (Watt) } \\
\left(\mathrm{W} \times \mathrm{kg}^{-1}\right)\end{array}$ & $\begin{array}{l}425 \pm 30.89 \\
5.05 \pm 0.35\end{array}$ & $\begin{array}{l}425 \pm 28.98 \\
5.09 \pm 0.29\end{array}$ & $\begin{array}{l}409 \pm 26.8 \\
4.71 \pm 0.41\end{array}$ & $\begin{array}{l}414 \pm 34.24 \\
5.10 \pm 0.27\end{array}$ \\
\hline$L A_{\min }\left(m m o l \times L^{-1}\right)^{a}$ & $1.8 \pm 0.23$ & $1.9 \pm 0.27$ & $1.7 \pm 0.23$ & $1.7 \pm 0.34$ \\
\hline$L A_{\max }\left(m m o l \times L^{-1}\right)^{a}$ & $13.8 \pm 1.96$ & $10.7 \pm 1.87$ & $13.6 \pm 2.11$ & $10.2 \pm 3.34$ \\
\hline Time (s) & $375.2 \pm 9.43$ & $374.4 \pm 8.63$ & $379.6 \pm 8.35$ & $378.1 \pm 10.45$ \\
\hline
\end{tabular}

Values represent means \pm standard deviations. ${ }^{a} \mathrm{LA}$, lactate acid. No statistically significant differences were found between the pre- and post-supplementation results $(P<0.05)$ 

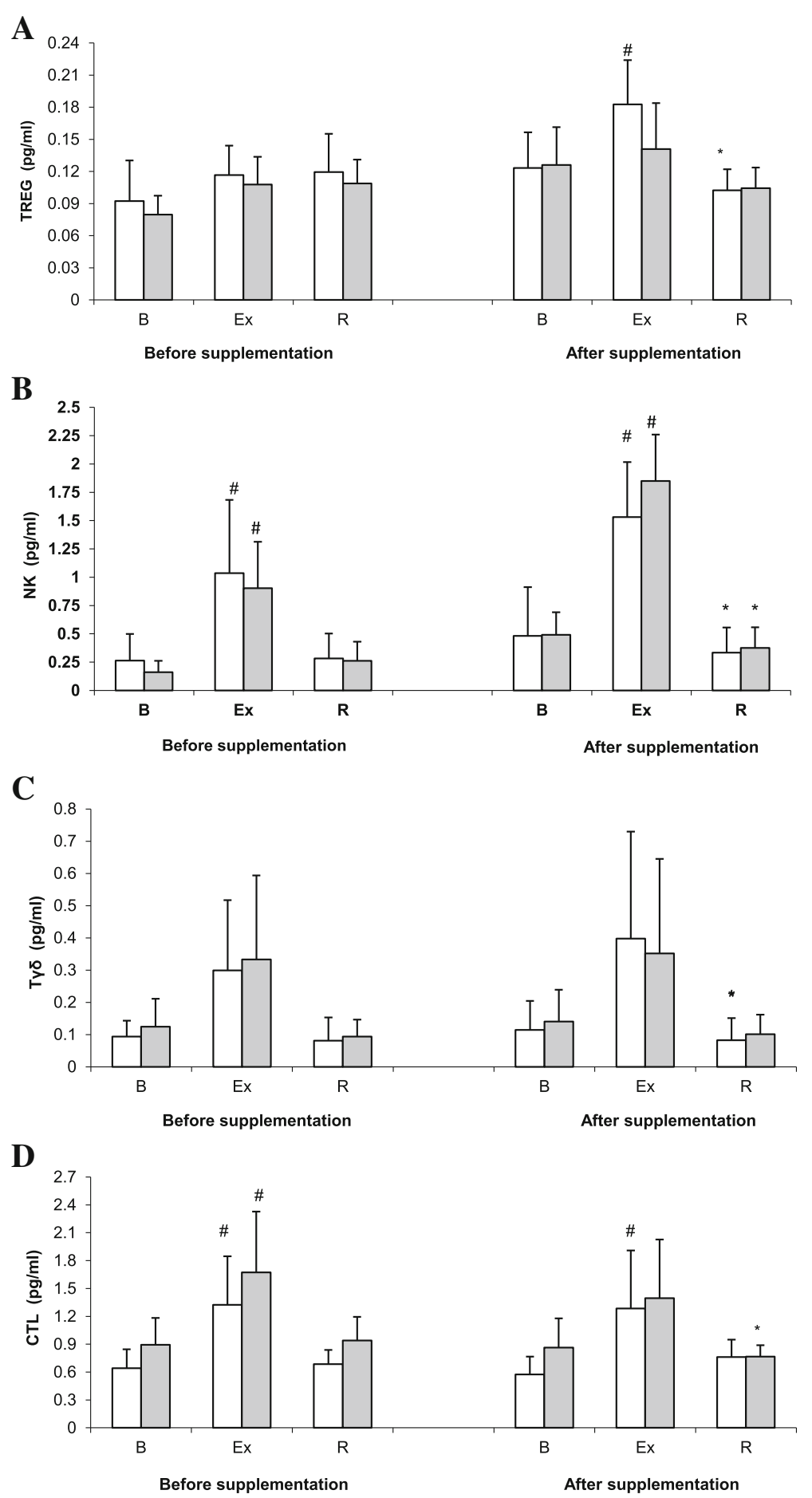

Fig. 1 Changes in Treg (a), NK cell (b), T $\delta \gamma$ cell (c) and CTL (d) counts during exercise tests performed prior to and after the supplementation

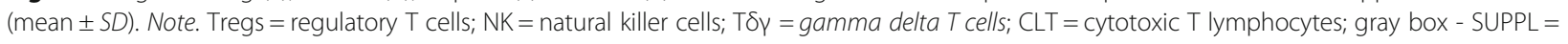
supplemented group; $\square$ - PLA = placebo group; $B$ = baseline; $E x=$ post-exercise; $R=$ after a 1-day recovery; \# - significantly different compared to the baseline level; * - significantly different compared to the post-exercise level

Values of the Treg/(NK $+\mathrm{T} \delta \gamma+\mathrm{CTL})$ ratio are presented on Fig. 2a. During the 1st examination, a significant post-recovery increase in $\mathrm{Treg} /(\mathrm{NK}+\mathrm{T} \delta \gamma+$
CTL) ratio was observed in both study groups. In turn, during the 2nd examination, post-exercise values of $\mathrm{Treg} /(\mathrm{NK}+\mathrm{T} \delta \gamma+\mathrm{CTL})$ ratio in the 

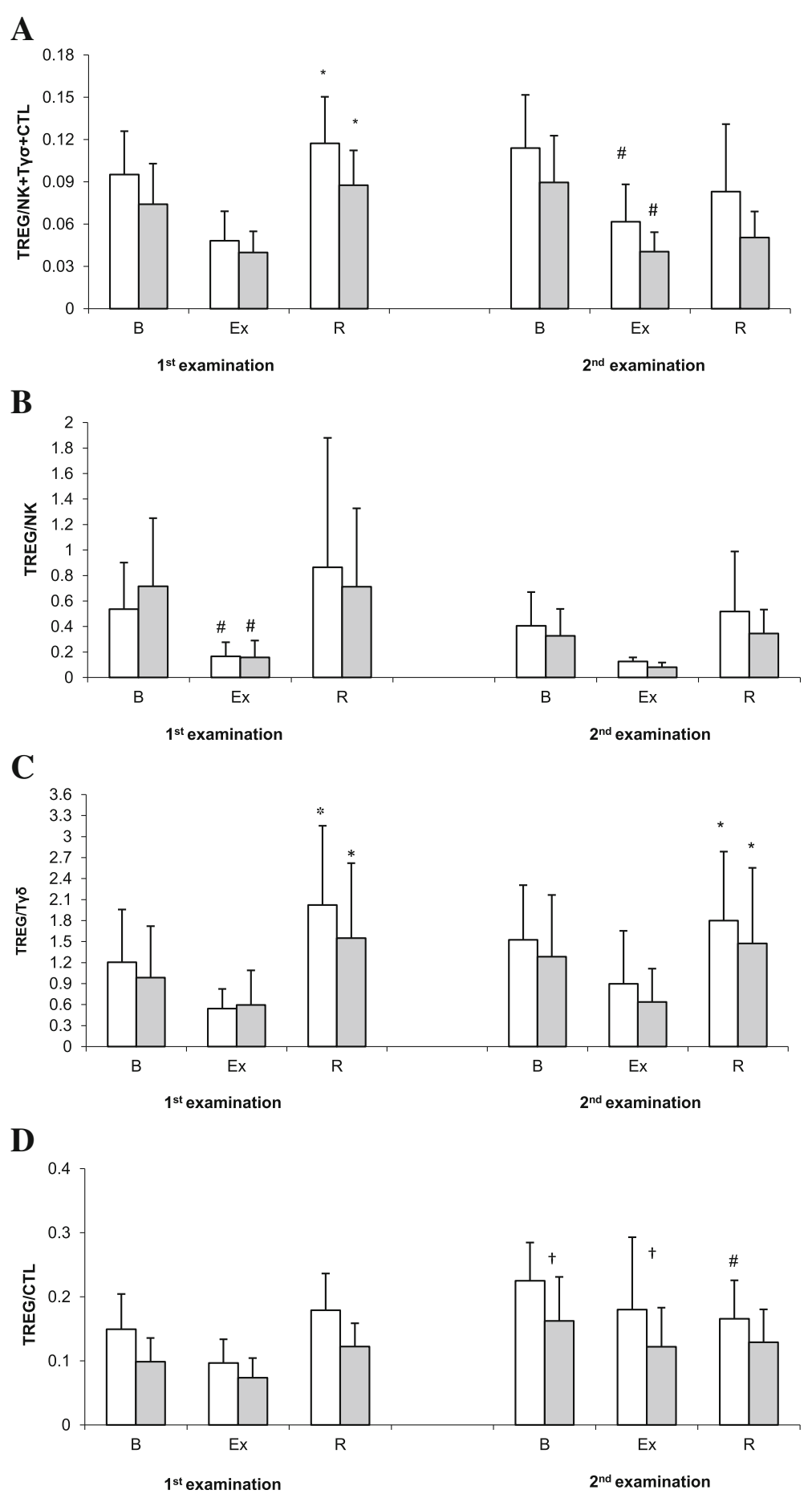

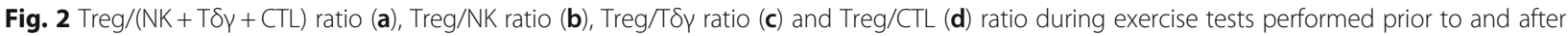
the supplementation (mean $\pm S D$ ). Note. Tregs = regulatory $T$ cells; NK= natural killer cells; $T \delta \gamma=$ gamma delta $T$ cells; $C T L=c y t o t o x i c ~ T$

lymphocytes; gray box - SUPPL = supplemented group; $\square-\mathrm{PLA}=$ placebo group; $\mathrm{B}=$ baseline; Ex = post-exercise; $\mathrm{R}=$ after a 1-day recovery; \# significantly different compared to baseline level; ${ }^{*}$ - significantly different compared to post-exercise level; $\dagger-$ significantly different compared to PLA group

supplemented group and the placebo group turned out to be significantly lower than pre-exercise values of this parameter. Nevertheless, ANOVA showed that the main effect of supplementation on Treg/ $(\mathrm{NK}+\mathrm{T} \delta \gamma+\mathrm{CTL})$ ratio was not statistically significant $(p=0.563)$. 
Values of Treg/NK ratio were modulated solely by exercise. Specifically, the post-exercise values of this parameter in both study groups were significantly lower than preexercise levels (Fig. 2b). However, this relationship was observed solely during the 1st examination, as no significant exercise-induced changes in Treg/NK ratio were found during the 2nd examination. Supplementation exerted no significant effect on the values of Treg/NK ratio.

Exercise-induced changes in Treg/T $\delta \gamma$ ratio are presented in Fig. 2c. Irrespective of the study group, strenuous physical exercise contributed to statistically significant changes in this parameter during both the 1st and the 2nd examination (main effect, $p<0.001$ ). The post-recovery increase in Treg/T $\delta \gamma$ ratio in the supplemented and control group corresponded to $154 \%$ and $274 \%$, respectively, prior to the supplementation, and to $133 \%$ and $101 \%$, respectively, after the supplementation. Based on the results of ANOVA, spirulina supplementation did not exert a statistically significant effect on $\mathrm{Treg} / \mathrm{T} \delta \gamma$ ratio (main effect, $p=0.129$ ).

Statistical analysis showed that both exercise and supplementation exerted a significant main effect on the values of Treg/CTL ratio ( $p=0.01$ and $p<0.001$, respectively) (Fig. 2d). Irrespective of the group, no statistically significant changes in this parameter were documented during the 1st examination. However, during the 2nd examination, a significant post-recovery decrease in this parameter was observed in the supplemented group, but not in the placebo group. Furthermore, post-exercise and post-recovery values of Treg/CTL ratio in supplemented athletes turned out to be significantly lower than in subjects from the placebo group.

\section{Discussion}

During the 2nd examination, a significant post-exercise increase in Treg count was observed solely in the placebo group, with subsequent normalization of this parameter after a 24-h recovery (Fig. 1a). Since lymphocytes are known to constantly migrate between the blood and other tissues, the post-exercise increase in circulating Tregs observed in the placebo group likely reflected a concomitant increase in the tissue count of these cells (Table 2). Previous research showed that Tregs may leave the circulation and migrate to lymph nodes and inflamed tissues $[46,47]$, whereby they mitigate the activity of cytotoxic cells and antigen presentation by dendritic cells (DCs) [48]. This local suppressive effect of Tregs may exert an unfavorable effect on systemic immunity. Morgado et al. [49] demonstrated that an increase in the training loads of swimmers contributed to a significant reduction of cytokine synthesis by monocytes and dendritic cells. Immune impairment associated with heavy training loads may occur primarily in immunologically active tissues, at least partially explaining the difficulties in identification of accurate markers of immunosuppression that could be determined in peripheral blood. Published evidence suggests that the immune impairment caused by escalation of training loads has no specific laboratory profile $[7,50,51]$. It should be emphasized that circulating lymphocytes represent only $2 \%$ of lymphocyte population; the vast majority of lymphocytes can be found in immunologically active tissues, such as lymph nodes, spleen, intestines, blood marrow, thymus and skin [52]. During heavy training, some tissue lymphocytes may migrate to the circulation in response to hormonal stimulation typical for strenuous exercise (e.g. catecholamines, cortisol). During post-exercise recovery, these lymphocytes migrate back to tissues, especially to those generating strong inflammatory/chemotactic signals [53]. This hypothesis seems to be supported by the postexercise increase in Treg count and subsequent postrecovery normalization of this parameter, observed during the 2nd examination in the placebo group (Fig. 1a).

ANOVA did not demonstrate a significant main effect of supplementation on Treg count; nevertheless, athletes from the supplemented group did not show a significant postexercise increase in this parameter during the 2nd examination (Fig. 1a). Therefore, it can be assumed that supplementation with SPR played a role in the maintenance of lower Treg counts in tissues, preventing immunosuppressive effect of these cells and restoring an immune balance.

During the 2nd examination, athletes from the supplemented group presented with significantly lower preexercise and post-exercise values of Treg/CTL ratio compared to subjects from the placebo group (Fig. 2d). Lower values of Treg/CTL ratio in the supplemented group might also reflect a beneficial effect of SPR supplementation. The decrease in this parameter implies that SPR might mitigate the inhibitory effect of Tregs on CTLs. Due to lesser immune deficit, athletes from the supplemented group might have been better protected against opportunistic infections and reactivation of latent viral infections (e.g., with CMV, EBV and HSV-1). In turn, higher values of Treg/CTL ratio in the placebo group might reflect an unfavorable shift in the "overtraining threshold" associated with a radical deterioration of immunity.

Irrespective of the examination term and the study group, we observed a significant post-recovery increase in Treg/T $\delta \gamma$ ratio (Fig. 2c). This effect was modulated solely by exercise. Nevertheless, during the 2nd examination we observed a significant post-recovery decrease in $\mathrm{T} \delta \gamma$ cell count in the placebo group, but not in the supplemented group (Fig. 1c). Due to presumable protective effect of SPR, preventing the post-recovery decrease in $T \delta \gamma$ cell count, strenuous exercise had probably less detrimental effect on the immune function in supplemented athletes. $\mathrm{T} \delta \gamma$ cells play a key role in antibacterial, antiviral and antitumor immunity. Published evidence suggests that the 
number of T $\delta \gamma$ cells is inter alia modulated by exercise intensity. Anane et al. [1] demonstrated that either high- or low-intensity exercise stimulated an increase in the number of circulating $\mathrm{T} \delta \gamma$ cells in previously untrained persons. However, another study showed that escalation of training loads during a winter training season resulted in a decrease in $T \delta \gamma$ cell counts in peripheral blood of elite swimmers [54].

Published data imply that SPR may exert a substantial effect on the activation of NK cells and their cytotoxic potential [35, 37, 43]. We did not observe a significant main effect of supplementation on either NK cell count (Fig. 1b) or Treg/NK ratio (Fig. 2b); however, irrespective of the examination term, strenuous exercise stimulated a significant increase in the number of NK cells (Fig. 1b).

According to a widely accepted concept, strenuous exercise stimulates migration of tissue lymphocytes to peripheral blood in a catecholamine-dependent mechanism. This hypothesis is inter alia supported by an increase in circulating lymphocyte count observed after infusion of epinephrine $[55,56]$. However, the fact that the post-exercise increase in lymphocyte count in elite athletes was less evident than in untrained persons, implies that immune response of the former group to strenuous exercise may be weaker $[57,58]$.

Post-exercise changes in lymphocyte count in intensively trained athletes were markedly less evident than in untrained persons, and less pronounced than it could be expected based on epinephrine and cortisol concentrations. However, published evidence suggests that changes in hormonal parameters do not necessarily correlate with lesser mobilization of tissue lymphocytes and their migration to peripheral blood $[8,10]$. Therefore, lesser responsiveness of tissue lymphocytes from elite athletes to strenuous exercise was interpreted as a consequence of training-induced changes, such as a decrease in the reactivity of $§ 2$-adrenergic receptors on these cells, altered expression of adhesive molecules or their ligands $[57,58]$.

However, in our opinion, also other potential mechanisms contributing to reduced mobilization of tissue lymphocytes after strenuous exercise need to be considered. According to a widely accepted and empirically verified hypothesis, various stimuli (among them physical exercise and infections) may induce bidirectional flow of lymphocytes from/to tissues (spleen, muscles, lungs, bone marrow) [9]. Adams et al. [9] showed that exercise promotes rapid migration of tissue lymphocytes (primarily from the spleen and lungs) to the circulation, along with markedly less evident shift of these cells from muscles to blood. Although this observation originates from a study in rats, the post-exercise increase in circulating lymphocyte counts in humans may also, to a certain degree, reflect higher absolute number of these cells in the spleen and lungs (and to a lesser extent, in muscles). Less evident post-exercise migration of lymphocytes to the peripheral blood of well-trained athletes may be associated with lower number of cytotoxic cells in their spleen and lungs, and/or with higher number of tissue Tregs. The latter hypothesis is also supported by the results of our study, which demonstrated a significant post-exercise increase in Treg count in the placebo group during the 2nd examination. However, also lymphopenia, observed few hours post-exercise as a consequence of the recirculation of blood lymphocytes to tissues (only $<10 \%$ of circulating lymphocytes undergo apoptosis), is a well-established phenomenon [10]. During post-exercise recovery of welltrained athletes, their lymphocytes may primarily recirculate to the muscles; due to multiple training-induced microinjuries, muscle tissue synthesizes large volumes of cytokines which act as a chemoattractant for peripheral lymphocytes $[59,60]$.

According to Adams et al. [9], recirculation of lymphocytes from muscles to the blood is less pronounced and slower than between spleen or lungs and peripheral circulation. Probably, lymphocytes of well-trained athletes may remain anchored in muscles for a longer time, which makes them less prone to recirculation and more susceptible to apoptosis. This may result in permanent loss of some cytotoxic lymphocytes from the spleen and lungs. However, the exact reason behind a post-exercise increase in Treg count in well-trained athletes is still unclear. Perhaps, this phenomenon is associated with an increase in IL-2 (synthesized by T cells in response to repeated strenuous exercise), stabilization of Foxp3, longer survival of mature Tregs, and resultant increase in their number in some tissues $[61,62]$.

Our findings suggest that another, yet unidentified mechanism may exist behind the post-exercise immune impairment observed in elite athletes subjected to heavy training loads. Higher number of circulating Tregs may reflect their increased counts in immunologically active organs, presumably in the spleen and lungs. The number of these tissue Tregs that migrate to the circulation during strenuous exercise may be higher than the number of migratory cytotoxic $\mathrm{T}$ lymphocytes (other than NK cells). Furthermore, it cannot be excluded that immunologically active organs are not only abundant in Tregs, but also contain less cytotoxic lymphocytes (T $\delta \gamma, \mathrm{CTL})$. During strenuous exercise, these sparse cytotoxic cells may migrate to other tissues (primarily muscles) whereby they undergo apoptosis, which probably also contributes to a post-exercise immunity impairment.

Our present study showed, for the first time, that supplementation with SPR may modulate some components of the immune system in athletes exposed to repeated strenuous exercise. The fact that rowers from the supplemented group did not show a post-exercise increase in 
Treg count (Fig. 1a) implies that SPR may play a role in maintaining normal tissue level of these cells during strenuous exercise, thus preventing immunosuppression. Moreover, SPR seemed to attenuate a suppressive effect of Tregs on CTLs, since during the 2nd examination, athletes from the supplemented group presented with significantly lower pre-exercise and post-exercise values of Treg/CTL ratio than subjects from the placebo group. Finally, strenuous physical exercise did not exert a significant effect on T $\delta \gamma$ cell count in the supplemented group, whereas athletes from the placebo group showed a postrecovery decrease in this parameter. Altogether, these findings suggest that supplementation with SPR may exert a beneficial effect on selected components of the immune system in athletes exposed to heavy training loads.

Future studies should center around better understanding of the mechanisms of immune impairment activated during and after strenuous exercise. Another direction of future research should be the identification of factors that may counterbalance the unfavorable consequences of exposure to maximal training loads.

\section{Conclusions}

The results of this study imply that supplementation with SPR extract might prevent a post-exercise increase in Treg counts and a post-recovery decrease in the number of $\mathrm{T} \delta \gamma$ cells, which contributed to lower Treg/CTL preexercise and post-exercise values ratio during the 2 nd examination. Altogether, these findings suggest that supplementation with SPR extract may protect athletes against a deficit in immune function (especially, antiinfectious function) associated with strenuous exercise, and may cause a beneficial shift in an "overtraining threshold" that prevents a radical deterioration of immunity.

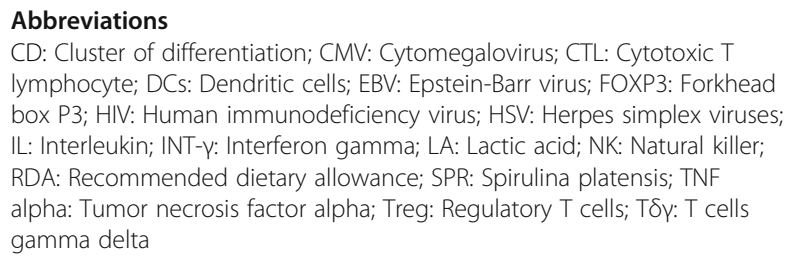

\section{Acknowledgments}

We thank all subjects for cooperation with the research.

\section{Funding}

The experiment was founded by knowledge grant of Polish Ministry of Science and Higher Education No 0034/RS3/2015/53.

\section{Availability of data and materials}

The datasets used and/or analyzed during the current study is available from the corresponding author on reasonable request.

\section{Authors' contributions}

The present study was designed by ASS and AJ; data were collected by PB, $J \mathrm{~J}, \mathrm{~K} \nless$; data interpretation and manuscript preparation were undertaken by AJ, ASS, EP and BM. All authors approved the final version of the paper.

\section{Ethics approval and consent to participate}

The experimental procedures and potential risks were explained to the participants and a written informed consent was provided and signed prior to inclusion in the study. The study was conducted in accordance with the Declaration of Helsinki, and the protocol was approved by the Ethics Committee of the Poznan University of Medical Sciences (act 769/13 archived number 10/October/2013).

\section{Consent for publication \\ Not applicable.}

\section{Competing interests}

The authors declare no conflict of interest, financial or otherwise. The authors declare that the results of the study are presented clearly, honestly, and without fabrication, falsification, or inappropriate data manipulation.

\section{Publisher's Note}

Springer Nature remains neutral with regard to jurisdictional claims in published maps and institutional affiliations.

\section{Author details}

'Department of Morphological and Health Sciences, Faculty of Physical Culture in Gorzów WIkp. Poland, 13 Estkowskiego Str.66 - 400, Gorzów WIkp, Poland. ${ }^{2}$ Department of Water Sports, Faculty of Physical Culture in Gorzów Wlkp. Poland, 13 Estkowskiego Str, 66 - 400 Gorzów Wlkp, Poland.

${ }^{3}$ Department of Pediatrics, Endocrinology, Diabetology, Metabolic Disorders and Cardiology of Developmental Age, Pomeranian Medical University, 1 Unii Lubelskiej Str, 71-252 Szczecin, Poland. ${ }^{4}$ Department of General Pathology, Pomeranian Medical University, 72 Al. Powstanców Wlkp. Str, 70-111 Szczecin, Poland. ${ }^{5}$ Department of Morphological and Health Sciences, Faculty of Physical Culture in Gorzów WIkp. Poland, 13 Estkowskiego Str, 66 400 Gorzów Wlkp, Poland.

Received: 11 September 2017 Accepted: 13 February 2018

Published online: 20 February 2018

\section{References}

1. Anane LH, Edwards KM, Burns VE, Drayson MT, Riddell NE, van Zanten JV, Wallace GR, Mills PJ, Bosch JA. Mobilization of gammadelta T lymphocytes in response to psychological stress, exercise, and beta-agonist infusion. Brain Behav Immun. 2009;23(6):823-9.

2. Pedersen BK, Hoffman-Goetz L. Exercise and the immune system: regulation, integration, and adaptation. Physiol Rev. 2000;80(3):1055-81.

3. Walsh NP, Gleeson M, Pyne DB, Nieman DC, Dhabhar FS, Shephard RJ, Oliver SJ, Bermon S, Kajeniene A. Position statement. Part two: maintaining immune health. Exerc Immunol Rev. 2011;17:64-103.

4. Nieman DC. Is infection risk linked to exercise workload? Med Sci Sports Exerc. 2000;32(7 Suppl):S406-11.

5. Gleeson M, Pyne DB. Respiratory inflammation and infections in highperformance athletes. Immunol Cell Biol. 2016;94(2):124-31.

6. Gleeson M, Bishop N, Oliveira M, McCauley T, Tauler P, Muhamad AS. Respiratory infection risk in athletes: association with antigen-stimulated IL-10 production and salivary lgA secretion. Scand J Med Sci Sports. 2012;22(3):410-7.

7. Peake JM, Neubauer O, Della Gatta PA, Nosaka K. Muscle damage and inflammation during recovery from exercise. J Appl Physiol. 2016;122(3): 559-70

8. Krüger K, Lechtermann A, Fobker M Völker K, Mooren FC. Exercise-induced redistribution of $\mathrm{T}$ lymphocytes is regulated by adrenergic mechanisms. Brain Behav Immun. 2008;22(3):324-38.

9. Adams GR, Zaldivar FP, Nance DM, Kodesh E, Radom-Aizik S, Cooper DM. Exercise and leukocyte interchange among central circulation, lung, spleen, and muscle. Brain Behav Immun. 2011;25(4):658-66.

10. Witard OC, Turner JE, Jackman SR, Tipton KD, Jeukendrup AE, Kies AK, Bosch JA. High-intensity training reduces $C D 8+T$-cell redistribution in response to exercise. Med Sci Sports Exerc. 2012;44(9):1689-97.

11. Beyer M, Classen S, Endl E, Kochanek M, Weihrauch MR, Debey-Pascher S, Knolle PA, Schultze JL. Comparative approach to define increased regulatory T cells in different cancer subtypes by combined assessment of CD127 and FOXP3. Clin Dev Immunol. 2011;2011:734036. https://doi.org/10.1155/2011/734036. 
12. Bui JD, Uppaluri R, Hsieh C, Schreiber RD. Comparative analysis of regulatory and effector T cells in progressively growing versus rejecting tumors of similar origins. Cancer Res. 2006;66(14):7301-9.

13. Chattopadhyay S, Mehrotra S, Chhabra A, Hegde U, Mukherij B, Chakraborty $N$. Effect of CD4+CD25+ and CD4+CD25- T regulatory cells on the generation of cytolytic $T$ cell response to a self but human tumorassociated epitope in vitro. J Immunol. 2006;176(2):984-90.

14. Kukreja A, Cost G, Marker J, Zhang C, Sun Z, Lin-Su K, Ten S, Sanz M, Exley M, Wilson B, Porcelli S, Maclaren N. Multiple immuno-regulatory defects in type-1 diabetes. J Clin Invest. 2002;109(1):131-40.

15. Mills KG. Regulatory T cells: friend or foe in immunity to infection? Nat Rev Immunol. 2004;4(11):841-55.

16. Miyara M, Amoura Z, Parizot C, Badoual C, Dorgham K, Trad S, Kambouchner M, Valeyre D, Chapelon-Abric C, Debré P, Piette JC, Gorochov G. The immune paradox of sarcoidosis and regulatory T cells. J Exp Med. 2006;203(2):359-70.

17. Sato E, Olson SH, Ahn J, Bundy B, Nishikawa H, Qian F, Jungbluth AA, Frosina D, Gnjatic S, Ambrosone C, Kepner J, Odunsi T, Ritter G, Lele S, Odunsi K. Intraepithelial CD8+ tumor-infiltrating lymphocytes and a high $\mathrm{CD} 8+$ /regulatory $\mathrm{T}$ cell ratio are associated with favorable prognosis in ovarian cancer. Proc Natl Acad Sci U S A. 2005;102(51):18538-43.

18. Smyth MJ, Teng ML, Swann J, Kyparissoudis K, Godfrey DI, Hayakawa Y. CD4 +CD25+ T regulatory cells suppress NK cell-mediated immunotherapy of cancer. J Immunol. 2006;176(3):1582-7.

19. Zou W. Regulatory T cells, tumor immunity and immunotherapy. Nat Rev Immunol. 2006;6(4):295-307.

20. Spychalski $Ł$. [Regulatory T lymphocytes in a microenvironment of pleural effusion in lung cancer. Doctoral dissertation from the Department of Pulmonology, Allergology and Pulmonological Oncology]. Poznan 2010.

21. Hoffmann P, Ermann J, Edinger M, Fathman CG, Strober S. Donor-type $\mathrm{CD} 4(+) \mathrm{CD} 25(+)$ regulatory T cells suppress lethal acute graft-versus-host disease after allogeneic bone marrow transplantation. J Exp Med. 2002; 196(3):389-99.

22. Piccirillo CA, Shevach EM. Cutting edge: control of CD8+ T cell activation by CD4+CD25+ immunoregulatory cells. J Immunol. 2001;167(3):1137-40.

23. Trzonkowski P, Szmit E, Myśliwska J, Dobyszuk A, Myśliwski A. CD4 $+\mathrm{CD} 25+\mathrm{T}$ regulatory cells inhibit cytotoxic activity of T CD8+ and NK lymphocytes in the direct cell-to-cell interaction. Clin Immunol. 2004; 112(3):258-67.

24. Ghiringhelli F, Ménard C, Terme M, Flament C, Taieb J, Chaput N, Puig PE, Novault S, Escudier B, Vivier E, Lecesne A, Robert C, Blay JY, Bernard J, Caillat-Zucman S, Freitas A, Tursz T, Wagner-Ballon O, Capron C, Vainchencker W, Martin F, Zitvogel L. CD4+CD25+ regulatory T cells inhibit natural killer cell functions in a transforming growth factor-beta-dependent manner. J Exp Med. 2005;202(8):1075-85.

25. Sakaguchi $S$. Naturally arising $C D 4+$ regulatory $T$ cells for immunolgic selftolerance and negative control of immune responses. Ann Rev Immunol. 2004;22(1):531-62.

26. Kunzmann V, Kimmel B, Herrmann T, Einsele H, Wilhelm M. Inhibition of phosphoantigen-mediated gammadelta T-cell proliferation by CD4+ CD25+ FoxP3+ regulatory T cells. Immunol. 2009;126(2):256-67.

27. Handzlik MK, Shaw AJ, Dungey M, Bishop NC, Gleeson M. The influence of exercise training status on antigen-stimulated IL-10 production in whole blood culture and numbers of circulating regulatory T cells. Eur J Appl Physiol. 2013;113(7):1839-48.

28. Gleeson M, Bishop NC. The T cell and NK cell immune response to exercise. Ann Transplant. 2005;10(4):43-8.

29. Steensberg A, Toft AD, Bruunsgaard H, Sandmand M, Halkjaer-Kristensen J, Pedersen BK. Strenuous exercise decreases the percentage of type $1 \mathrm{~T}$ cells in the circulation. J Appl Physiol. 2001;91(4):1708-12.

30. Wang J, Song $H$, Tang $X$, Yang $Y$, Vieira VJ, Niu Y, Ma Y. Effect of exercise training intensity on murine T-regulatory cells and vaccination response. Scan J Med Sci Sports. 2012;22(5):643-52.

31. Wilson LD, Zaldivar FP, Schwindt CD, Wang-Rodriguez J, Cooper DM. Circulating T-regulatory cells, exercise and the elite adolescent swimmer. Pediatr Exerc Sci. 2009;21 (3):305-17.

32. Perry C, Pick M, Bdolach N, Hazan-Halevi I, Kay S, Berr I, Reches A, Harishanu Y, Grisaru D. Endurance exercise diverts the balance between Th17 cells and regulatory T cells. PLoS One. 2013;8(10):e74722.

33. Borowitzka MME, Gershwin A. Spirulina in human nutrition and health. J Appl Phycol. 2009;21(6):747-8.
34. Wu Q, Liu L, Miron A, Klímová B, Wan D, Kuča K. The antioxidant, immunomodulatory, and anti-inflammatory activities of spirulina: an overview. Archiv Toxicol. 2016;90(8):1817-40.

35. Akao Y, Ebihara T, Masuda H, Saeki Y, Akazawa T, Hazeki K, Matsumoto M, Seya T. Enhancement of antitumor natural killer cell activation by orally administered spirulina extract in mice. Cancer Sci. 2009;100(8):1494-501.

36. Tornabene T, Bourne T, Raziuddin S, Ben-Amotz A. Lipid and lipopolysaccharide constituents of cyanobacterium Spirulina Platensis (Cyanophyceae, Nostocales). Mar Ecol Prog Ser. 1985;22:121-5.

37. Hirahashi T, Matsumoto M, Hazeki K, Saeki Y, Ui M, Seya T. Activation of the human innate immune system by spirulina: augmentation of interferon production and NK cytotoxicity by oral administration of hot water extract of Spirulina Platensis. Int Immunopharmacol. 2002;2(4):423-34.

38. Ayehunie S, Belay A, Baba TW, Ruprecht RM. Inhibition of HIV-1 replication by an aqueous extract of Spirulina Platensis (Arthrospira Platensis). J Acquir Immune Defic Syndr. 1998;18(1):7-12.

39. Hayashi K, Hayashi T, Kojima I. A natural sulfated polysaccharide, calcium spirulan, isolated from Spirulina Platensis: in vitro and ex vivo evaluation of anti-herpes simplex virus and anti-human immunodeficiency virus activities. AIDS Res Hum Retrovir. 1996;12(15):1463-71.

40. Løbner M, Walsted A, Larsen R, Bendtzen K, Nielsen CH. Enhancement of human adaptive immune responses by administration of a high-molecularweight polysaccharide extract from the cyanobacterium Arthrospira Platensis. J Med Food. 2008;11(2):313-22.

41. Maerten P, Shen C, Bullens DA, Van Assche G, Van Gool S, Geboes K, Rutgeerts $P$, Ceuppens JL. Effects of interleukin 4 on CD25+CD4+ regulatory T cell function. J Autoimmun. 2005;25(2):112-20.

42. Mao TK, Van de Water J, Gershwin ME. Effects of a spirulina-based dietary supplement on cytokine production from allergic rhinitis patients. J Med Food. 2005:8(1):27-30.

43. Nielsen $\mathrm{CH}$, Balachandran $\mathrm{P}$, Christensen $\mathrm{O}$, Pugh ND, Tamta $\mathrm{H}$, Sufka K, Wu X, Walsted A, Schjørring-Thyssen M, Enevold C, Pasco DS. Enhancement of natural killer cell activity in healthy subjects by Immulina ${ }^{\oplus}$, a spirulina extract enriched for Braun-type lipoproteins, Planta Med. 2010;76(16):802-8.

44. Gao Q, Qiu S, Fan J, Zhou J, Wang X, Xiao Y, Xu Y, Li Y, Tang Z. Intratumoral balance of regulatory and cytotoxic $T$ cells is associated with prognosis of hepatocellular carcinoma after resection. J Clin Oncol. 2007:25(18):2586-93.

45. Jarosz M. Nutrition standards for the polish population - amendment. Warszawa: Copyright by Instytut Żywności i Żywienia; 2012.

46. Huehn J, Siegmund K, Lehmann JU, Siewert C, Haubold U, Feuerer M, Debes GF, Lauber J, Frey O, Przybylski GK, Niesner U, de la Rosa M, Schmidt CA, Bräuer R, Buer J, Scheffold A, Hamann A. Developmental stage, phenotype, and migration distinguish naive- and effector/memory-like CD4 + regulatory T cells. J Exp Med. 2004;199(3):303-13.

47. Menning A, Höpken UE, Siegmund K, Lipp M, Hamann A, Huehn J. Distinctive role of CCR7 in migration and functional activity of naive- and effector/memory-like Treg subsets. Eur J Immunol. 2007;37(6):1575-83.

48. Zhang N, Schröppel B, Lal G, Jakubzick C, Mao X, Chen D, Yin N, Jessberger $R$, Ochando JC, Ding Y, Bromberg JS. Regulatory T cells sequentially migrate from inflamed tissues to draining lymph nodes to suppress the alloimmune response. Immunity. 2009;30(3):458-69.

49. Morgado JM, Rama L, Silva I, de Jesus Inácio M, Henriques A, Laranjeira P, Pedreiro S, Rosado F, Alves F, Gleeson M, Pais ML, Paiva A, Teixeira AM. Cytokine Production by monocytes, neutrophils, and dendritic cells is hampered by long-term intensive training in elite swimmers. Eur J Appl Physiol. 2012;112(2):471-82.

50. Gabriel HH, Urhausen A, Valet G, Heidelbach U, Kindermann W. Overtraining and immune system: a prospective longitudinal study in endurance athletes. Med Sci Sports Exerc. 1998;30(7):1151-7.

51. Rowbottom DG, Keast D, Goodman C, Morton AR. The haematological, biochemical and immunological profile of athletes suffering from the overtraining syndrome. Eur J Appl Physiol Occup Physiol. 1995;70(6):502-9.

52. Blum KS, Pabst R. Lymphocyte numbers and subsets in the human blood. Do they mirror the situation in all organs? Immunol Lett. 2007;108(1):45-51.

53. Dhabhar FS, Miller AH, Spencer RL. Stress-induced changes in blood leukocyte distribution. Role of adrenal steroid hormones. J Immunol. 1996; 157(4):1638-44

54. Teixeira AM, Rama L, Carvalho HM, Borges G, Carvalheiro T, Gleeson M, Alves F, Trindade H, Paiva A. Changes in naive and memory T-cells in elite swimmers during a winter training season. Brain Behav Immun. 2014;39:186-93. 
55. Dimitrov S, Lange T, Bom J. Selective mobilization of cytotoxic leukocytes by epinephrine. J Immunol. 2010;184(I):503-II.

56. Karaszewski JW, Reder AT, Anlar B, Kim WC, Amason BG. Increased lymphocyte beta-adrenergic receptor density in progressive multiple sclerosis is specific for the CD8+, CD28- suppressor cell. Ann Neurol. 1991; 30(l):42-7.

57. Hong S, Johnson TA, Farag NH, Guy HJ, Matthews SC, Ziegler MG, Mills PJ. Attenuation of T-lymphocyte demargination and adhesion molecule expression in response to moderate exercise in physically fit individuals. J Appl Physiol. 2005;98(3):1057-63.

58. Mills PJ, Hong S, Redwine L, Carter SM, Chiu A, Ziegler MG, Dimsdale JE, Maisel AS. Physical fitness attenuates leukocyte-endothelial adhesion in response to acute exercise. J Appl Physiol. 2006;101(3):785-8.

59. Paulsen G, Crameri R, Benestad HB, Fjeld JG, Mørkrid L, Hallén J, Raastad T. Time course of leukocyte accumulation in human muscle after eccentric exercise. Med Sci Sports Exerc. 2010;42(1):75-85.

60. Tidball JG, Villalta SA. Regulatory interactions between muscle and the immune system during muscle regeneration. Am J Physiol Regul Integr Comp Physiol. 2010;298(5):R1173-87.

61. Chinen T, Kannan AK, Levine AG, Fan X, Klein U, Zheng Y, Gasteiger G, Feng Y, Fontenot JD, Rudensky AY. An essential role for the IL-2 receptor in Treg cell function. Nat Immunol. 2016;7(11):1322-33.

62. Setoguchi R, Hori S, Takahashi T, Sakaguchi S. Homeostatic maintenance of natural $3(+) \mathrm{CD} 25(+) \mathrm{CD} 4(+)$ regulatory T cells by interleukin (IL)-2 and induction of autoimmune disease by IL-2 neutralization. J Exp Med. 2005; 201(5):723-35.

\section{Submit your next manuscript to BioMed Central} and we will help you at every step:

- We accept pre-submission inquiries

- Our selector tool helps you to find the most relevant journal

- We provide round the clock customer support

- Convenient online submission

- Thorough peer review

- Inclusion in PubMed and all major indexing services

- Maximum visibility for your research

Submit your manuscript at www.biomedcentral.com/submit
Biomed Central 